\title{
Suitable habitat for recolonizing large carnivores in the midwestern USA
}

\author{
Julia B. Smith, Clayton K. Nielsen and Eric C. Hellgren
}

\begin{abstract}
Large carnivores are recolonizing parts of North America and Europe as a result of modern management and conservation policy. In the midwestern USA, black bears Ursus americanus, cougars Puma concolor and grey wolves Canis lupus have the potential to recolonize provided there is suitable habitat. Understanding where large carnivores may become re-established will prepare resource professionals for the inevitable ecosystem effects and potential human-carnivore conflicts associated with these species. We developed individual and combined models of suitable habitat for black bears, cougars and wolves in 18 midwestern states, using geospatial data, expert-opinion surveys, and multi-criteria evaluation. Large, contiguous areas of suitable habitat comprised 35,21 and $13 \%$ of the study region for wolves, bears and cougars, respectively. Approximately $12 \%$ of the region was considered suitable for all three species. Arkansas, Minnesota, Texas and Wisconsin had the highest proportions $(>40 \%)$ of suitable habitat for black bears; Arkansas, Michigan, Missouri, Texas and Wisconsin had the highest proportions $(\geq 20 \%)$ of suitable habitat for cougars; and only in four states in the study region was $<29 \%$ of land suitable wolf habitat. Models performed well when validated by comparing suitability values of independent sets of known carnivore locations to those of random locations. Contiguous areas of suitable habitat typically spanned multiple states, thus coordination across boundaries and among agencies will be vital to successful conservation of these species. Our models highlight differences in habitat requirements and geographical distribution of potential habitat among these carnivores, as well as areas vital to their persistence in the Midwest.
\end{abstract}

Keywords Analytic hierarchy process, Canis lupus, geographical information system, GIS, habitat suitability, Midwest, Puma concolor, recolonize, Ursus americanus

To view supplementary material for this article, please visit http://dx.doi.org/10.1017/So030605314001227.

JuliA B. Smith (Corresponding author) Mexican Wolf Recovery Program, Arizona Game and Fish Department, Alpine, Arizona, USA

E-mail jbsmith@azgfd.gov

Clayton K. Nielsen Cooperative Wildlife Research Laboratory and Department of Forestry, Southern Illinois University Carbondale, Carbondale, Illinois, USA

ERIC C. HelLgren Department of Wildlife Ecology and Conservation, University of Florida, Gainesville, Florida, USA

Received 19 May 2014. Revision requested 28 August 2014.

Accepted 18 December 2014. First published online 1 July 2015.

\section{Introduction}

Dopulation decreases and range contractions of large carnivores are associated with habitat loss and high human density (Woodroffe, 2000; Laliberte \& Ripple, 2004). However, the implementation of modern management policy for the conservation of large carnivores in North America and Europe has shown that carnivore decline is a reversible trend (Linnell et al., 2001). Populations of large carnivores are recovering following decades of systematic extermination, a pattern observed in North America (Mech, 1995; Garshelis \& Hristienko, 2006; LaRue et al., 2012) and internationally (Swenson et al., 1995; Breitenmoser, 1998; Valière et al., 2003). Black bears Ursus americanus, cougars Puma concolor and grey wolves Canis lupus are the three most widespread large carnivores in the USA (Feldhamer et al., 2003). Populations of these species have persisted and proven capable of recolonizing areas of their former range despite extermination efforts, habitat fragmentation and varying levels of human-induced mortality (i.e. via harvest or vehicle collisions). Large carnivores have the potential to recolonize the midwestern USA (henceforth Midwest) provided there is substantial suitable habitat for them in the region. As public interest and media attention regarding the expansion of populations of large predators increase, a greater understanding of recolonization potential is necessary to make sound conservation, management and policy decisions.

Black bears, cougars and wolves are adaptable as habitat generalists and can thrive in a variety of environments provided they are tolerated by people. Black bear populations across North America are generally stable or increasing (Garshelis \& Hristienko, 2006). Cougar populations in the western USA have expanded since the 1960s (Sweanor et al., 2000). As a result, confirmations of cougars in the Midwest have increased significantly since 1990 and breeding populations have become re-established in states where the species was extirpated previously (LaRue et al., 2012). By 1960 the grey wolf had been eliminated in the USA except in Alaska, northern Minnesota, and Isle Royale (Paquet \& Carbyn, 2003). Following protection under the Endangered Species Act of 1973, wolves began to recolonize areas where they had been absent for decades, specifically in northern Wisconsin and Michigan's Upper Peninsula (Mech, 1995).

Recolonizing large carnivores will probably have significant effects on midwestern ecosystems. In particular, populations of white-tailed deer Odocoileus virginianus, the primary prey of cougars and wolves, are likely to be affected (DelGiudice et al., 2002; Robinson et al., 2002). Cougars and 
wolves may affect biodiversity and plant recruitment; both species have been linked to trophic cascades in multiple systems (Hebblewhite et al., 2005; Berger et al., 2008; Ripple \& Beschta, 2008). Furthermore, restoration of apex predators may influence the behaviour of smaller carnivores such as coyotes Canis latrans and could control effects of mesopredator release (Berger \& Gese, 2007; Prugh et al., 2009).

Understanding where breeding populations of large carnivores may become re-established, through an assessment of habitat suitability, will prepare wildlife managers for the impacts of these carnivores on midwestern ecosystems, in addition to potential human-carnivore conflicts. Although residents surveyed in midwestern states generally perceived a low level of risk from large carnivores, perception and tolerance of risk varied widely among groups (Smith et al., 2014). Although numerous models of suitable habitat for black bears, cougars, and wolves have been developed, there are no such models for these carnivores in the Midwest apart from that of LaRue \& Nielsen (2011). Furthermore, previous habitat models do not consider potential habitat for all three species. This information may provide the foundation for management plans in states where large carnivore populations have been absent for decades. Our objectives were to (1) model potential habitat for black bears, cougars and wolves in the Midwest; (2) delineate large areas of contiguous, highly favourable habitat; (3) assess overlap in contiguous, suitable areas for each species; and (4) assess the validity of the model.

\section{Methods}

We used expert information to develop predictive habitat models for black bears, cougars and wolves (Store \& Kangas, 2001). We used this approach rather than using empirical data to build the models because such datasets are generally not available or consistent across the Midwest; these carnivores do not yet exist in substantial numbers in the majority of the region. The model included 18 states from the central Great Plains to the upper Midwest and mid-South regions (Fig. 1). We selected these states because they included areas whence all three focal species were extirpated, and areas where there are breeding populations (e.g. the Black Hills of South Dakota for cougars). Inclusion of these states facilitated the mapping of areas where potential source populations exist as well as suitable habitat in areas where these carnivores do not exist at present.

We adapted a survey on the habitat requirements of the focal species from that developed by LaRue \& Nielsen (2011) to obtain expert knowledge. The survey (Supplementary Material 1) consisted of several questions regarding pair-wise comparisons of the following habitat variables: cover type, road density/distance to roads, human density, distance to water, and slope (Supplementary Table $\mathrm{S}_{1}$ ). We contacted furbearer biologists (19 in total) from each state included in our model, as well as university or agency researchers who specialized in black bear (12) or wolf (19) ecology. Survey participants were asked to score habitat variables, using the analytic hierarchy process (Saaty, 1980), in order of potential importance to each species on the basis of expert knowledge of carnivore ecology and midwestern habitats. Expert opinions from completed surveys were averaged for analysis and a consistency ratio was calculated to determine the consistency of answers among experts (Saaty, 1980).

We used digital data layers (all mosaics resampled to $90 \times 90 \mathrm{~m}$ pixels) to create geospatial datasets representative of midwestern landscapes to construct the habitat suitability models in ArcGIS v. 10 (ESRI, Redlands, USA). The 2006 National Land Cover Dataset (a land cover categorization scheme applied across the contiguous USA at a resolution of $30 \mathrm{~m}$; MRLC, 2006) consisted of 15 categories in the study region but we grouped similar cover types into eight categories: developed/barren and open water, deciduous forest, evergreen forest, mixed forest, shrubland, grassland, agricultural land, and wetland. Land cover categorization accuracy was $84 \%$ (Wickham et al., 2013).

We combined digital elevation model data (USGS, 2011) into a seamless layer and clipped the layer to the perimeter of the study area. Slope was calculated in degrees and categorized on the basis of the expert opinion surveys. We used the digital elevation model data and Arc Hydro Tools v. 2.0 (ESRI, Redlands, USA) to create stream shapefiles by filling the digital elevation model and calculating flow direction and flow accumulation. We buffered the stream shapefiles on the basis of distances identified in the expert opinion surveys.

Human-density data were based on census block groups (U.S. Census Bureau, 2010a). Road data (U.S. Census Bureau, 2010b) included all primary and secondary roads for each state in the study region. For the black bear model we applied a multiple ring buffer to all roads according to the distances identified in the expert survey. For the wolf model we used the Line Density tool in the Spatial Analyst extension to ArcGIS to calculate road density. We then converted all layers to raster format and recategorized them for consistency with the expert surveys.

We used multi-criteria evaluation to transform raw data into map layers by standardizing, combining and attributing weights to variables (Store \& Kangas, 2001). We evaluated responses from the expert knowledge surveys using matrices in Excel (Microsoft, Redmond, USA) to determine the relative importance of each habitat factor. Importance was based on an optimization method in which habitat factors were ranked using pair-wise comparisons as applied in the analytic hierarchy process (Saaty, 1980). Use of the analytic hierarchy process closely followed procedures from LaRue \& Nielsen (2011).

For black bears and wolves, habitat suitability was determined by recategorizing and weighting each habitat 

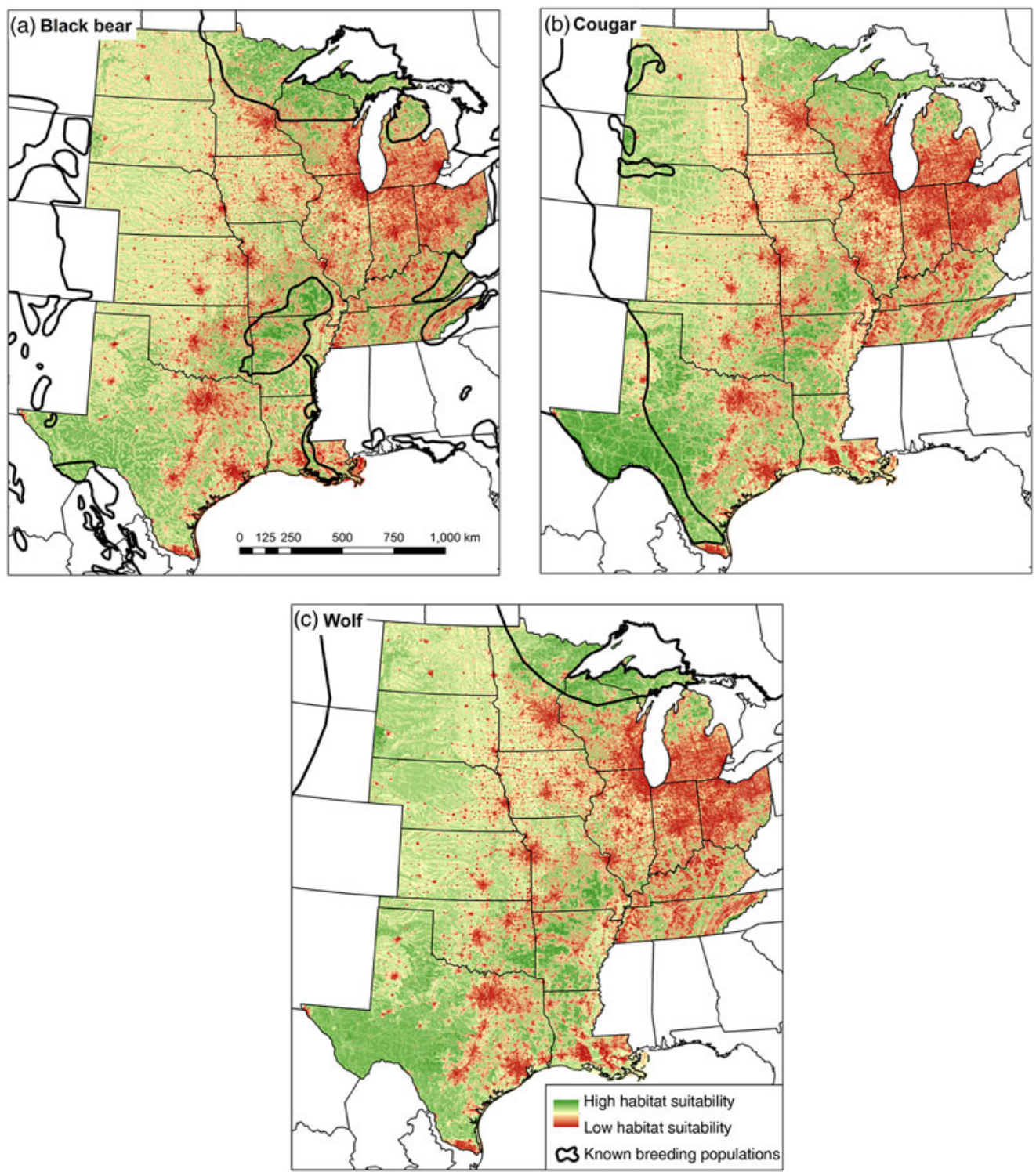

FIG. 1 Habitat suitability of the midwestern USA for (a) black bear Ursus americanus, (b) cougar Puma concolor and (c) wolf Canis lupus, based on expert knowledge.

factor on the basis of the averaged results of the expert surveys. We subsequently mapped these variables and their associated weights by overlay. We produced final maps of habitat for black bears and wolves, using raw scores calculated and averaged in the multi-criteria evaluation within the Raster Calculator (ESRI, Redlands, USA). For cougars, we incorporated the model of potential habitat in the Midwest created by LaRue \& Nielsen (2011) and added the nine states not included in the original model. Each pixel in each of the models was assigned a habitat suitability score of o-100, which was converted from raw scores.

We obtained known locations of black bears and wolves to define habitat suitability thresholds for each species and validate the models (Table 1). For each species we created a set of random locations equal to the number of actual locations, and used a Kolmogorov-Smirnov test $(\alpha=0.05)$ to compare the distribution of habitat suitability values associated with known locations of carnivores with the distribution of suitability values associated with each statewide sample of random locations. The Kolmogorov-Smirnov tests were used to validate the models for black bears and wolves; similar distributions of habitat suitability values between known locations and state-wide random locations would indicate that the habitat models do not predict carnivore habitat better than random. Details on the validation process for the cougar habitat model are in LaRue \& Nielsen (2011). We defined a habitat suitability threshold for black bears and wolves based on the mean minimum suitability percentage of the highest $90 \%$ of known locations; the mean value was $75 \%$ for both species. Thus, we considered pixels with habitat 
TABLE 1 Locations of black bear Ursus americanus (adult female) and wolf Canis lupus (adult male and female) used to define habitat suitability thresholds for each species and for habitat model validation, with state, species, number of locations, and source of data.

\begin{tabular}{|c|c|c|c|}
\hline State & Species & No. of locations & Source \\
\hline Michigan & Wolf & 18,188 & $\begin{array}{l}\text { Collected 2001-2010 (D. Beyer, Michigan Department of } \\
\text { Natural Resources, unpubl. data) }\end{array}$ \\
\hline \multirow{2}{*}{ Minnesota } & Black bear & 973 & Collected 2010, (Garshelis et al., 2011) \\
\hline & Wolf & 4,417 & $\begin{array}{l}\text { Collected } 2004 \text { and } 2008 \text { (J. Erb, Minnesota Department of } \\
\text { Natural Resources, unpubl. data) }\end{array}$ \\
\hline Oklahoma & Black bear & 814 & Collected 2001-2002 (Hellgren et al., 2007) \\
\hline \multirow[t]{2}{*}{ Wisconsin } & Black bear & 3,202 & Collected 2006-2008 (Malcolm, 2011) \\
\hline & Wolf & 2,942 & $\begin{array}{l}\text { Collected 2010-2011 (A. Wydeven, Wisconsin Department of } \\
\text { Natural Resources, unpubl. data) }\end{array}$ \\
\hline
\end{tabular}

suitability scores $\geq 75 \%$ as highly favourable habitat for black bears and wolves. Following procedures in LaRue \& Nielsen (2011), a suitability threshold of $\geq 75 \%$ was also used for cougars. We used this threshold to convert each suitability map to a binary classification of suitable/unsuitable habitat and, for each carnivore, subsequently mapped contiguous tracts of suitable habitat large enough to sustain a viable population. We considered a large, contiguous tract of habitat to be $\geq 300$ $\mathrm{km}^{2}$ for black bears, in concordance with Rogers \& Allen (1987), who suggested a population with 30-40 adult females would require an area of $288-385 \mathrm{~km}^{2}$. For wolves, we delineated contiguous areas of suitable habitat $\geq 500 \mathrm{~km}^{2}$ on the basis of the minimum reserve size necessary to maintain a viable population (Fritts \& Carbyn, 1995). On the basis of Beier (1993) and Belden \& Hagedorn (1993) and following LaRue \& Nielsen (2011), areas of suitable habitat $\geq 2,500$ $\mathrm{km}^{2}$ were designated as contiguous cougar habitat. We used the Region Group tool within the Spatial Analyst extension to group connected pixels with the same value (o or 1; i.e. unsuitable or suitable). We then eliminated from each model all pixel groups $<300 \mathrm{~km}^{2}$ for black bears, $<500 \mathrm{~km}^{2}$ for wolves and $<2,500 \mathrm{~km}^{2}$ for cougars, to create maps of contiguous, suitable habitat for each species. After converting the raster maps of contiguous habitat for each species to polygon layers, we overlaid these layers and calculated polygon intersections to quantify overlap in contiguous, suitable habitat for the three focal species.

\section{Results}

We received 12 black bear surveys (38.7\% return rate) and 14 wolf surveys ( $36.8 \%$ return rate). Consistency levels were high among surveyed experts, with the exception of scores assigning importance of distance to roads for bears (Table 2). Experts indicated that cover type was the most important variable for predicting potential habitat for black bears and cougars in the Midwest, followed by human density (Table 2). Human density was the most important variable for predicting wolf habitat, followed by cover type (Table 2). Forest cover and low human density were specified as suitable attributes for all three species and were characteristic of contiguous tracts of suitable habitat (Table 3). As attributes within the slope variable (steep, moderate or gentle) were ranked almost identically by experts in regard to wolf use, slope was not incorporated in the wolf habitat model.

Almost $32 \%$ of the study region contained suitable habitat for black bear; Arkansas, Minnesota, Texas and Wisconsin had $>40 \%$ suitable habitat (Supplementary Material 2, Fig. 1a). Large, contiguous areas of suitable habitat comprised $>21 \%$ of the study region (Supplementary Material 2, Fig. 2a). The largest contiguous tracts of suitable habitat for black bear were in west-central Texas, the northern Great Lakes region (Michigan, Minnesota and Wisconsin), the Missouri Ozarks, and the Arkansas Ozarks, Ouachitas and Coastal Plains (Supplementary Material 2, Fig. 2a). In most states there was extensive overlap between suitable habitat for bear and wolf, and some overlap with cougar habitat; across the study region $>56 \%$ of bear habitat overlapped with cougar habitat and almost 91\% overlapped with wolf habitat (Supplementary Material 3).

The mean habitat suitability value of pixels associated with black bear locations was $79 \%$ in Minnesota, $86 \%$ in Oklahoma and $77 \%$ in Wisconsin (79\% overall). The percentage of locations with $\geq 75 \%$ suitability was $78 \%$ in Minnesota, $97 \%$ in Oklahoma and $71 \%$ in Wisconsin ( $77 \%$ overall). The distributions of habitat suitability values associated with known locations of black bear and state-wide random locations differed for all three datasets $(D=0.412, \mathrm{P}<0.001$ for Minnesota; $D=0.700, \mathrm{P}<0.001$ for Oklahoma; $D=0.359$, $\mathrm{P}<0.001$ for Wisconsin)

Approximately $19 \%$ of the study region was considered suitable habitat for cougars. States with $\geq 20 \%$ suitable habitat for cougars were Arkansas, Michigan, Missouri, Texas and Wisconsin (Supplementary Material 2, Fig. 1b). Large, contiguous areas of suitable habitat represented c. $13 \%$ of the study region across seven areas: the North Dakota Badlands, South Dakota Black Hills, west-central Texas, the northern Great Lakes region (Michigan, Minnesota and Wisconsin), the Ozark region of Arkansas and Missouri, the Ouachita National Forest in Arkansas and Oklahoma, and the Daniel Boone National Forest 
TABLE 2 Weights (representing the averaged, relative scores of importance to potential carnivore habitat) and consistency ratio for variables used in the development of habitat suitability models for black bears, cougars Puma concolor and wolves in the midwestern USA in 2012.

\begin{tabular}{|c|c|c|c|}
\hline Variable & Species & Weight $\pm S D$ & Consistency ratio \\
\hline \multirow[t]{3}{*}{ Cover type } & Black bear & $1.71 \pm 0.58$ & 0.05 \\
\hline & Cougar & $1.84 \pm 0.59$ & 0.10 \\
\hline & Wolf & $1.39 \pm 0.82$ & 0.03 \\
\hline \multirow[t]{3}{*}{ Human density } & Black bear & $1.12 \pm 0.68$ & 0.04 \\
\hline & Cougar & $1.22 \pm 0.82$ & 0.06 \\
\hline & Wolf & $1.70 \pm 0.85$ & 0.06 \\
\hline \multirow[t]{3}{*}{ Distance to roads/road density } & Black bear & $0.72 \pm 0.37$ & 0.15 \\
\hline & Cougar & $0.86 \pm 0.45$ & 0.01 \\
\hline & Wolf & $1.04 \pm 0.55$ & 0.00 \\
\hline \multirow[t]{3}{*}{ Distance to water } & Black bear & $1.01 \pm 0.55$ & 0.04 \\
\hline & Cougar & $0.47 \pm 0.26$ & 0.02 \\
\hline & Wolf & $0.53 \pm 0.66$ & 0.01 \\
\hline \multirow[t]{3}{*}{ Slope } & Black bear & $0.43 \pm 0.34$ & 0.06 \\
\hline & Cougar & $0.61 \pm 0.56$ & 0.00 \\
\hline & Wolf & $0.34 \pm 0.28$ & 0.01 \\
\hline
\end{tabular}

${ }^{\star}$ Values $\leq$ o.10 indicate a consistency among expert opinions (Saaty, 1980).

TABLE 3 Mean values of habitat variables (human density, road density, forest, grassland/shrubland, agriculture, developed) associated with contiguous, suitable habitat for black bears, cougars and wolves in the midwestern United States, 2012.

\begin{tabular}{|c|c|c|c|c|c|c|}
\hline Species & $\begin{array}{l}\text { Human density } \\
\left(\mathrm{km}^{-2}\right)\end{array}$ & Road density $\left(\mathrm{km}\right.$ per $\left.\mathrm{km}^{2}\right)$ & Forest (\%) & Grassland/shrubland (\%) & Agriculture (\%) & Developed (\%) \\
\hline Black bear & 3.3 & 0.1 & 39.1 & 40.9 & 4.7 & 2.0 \\
\hline Cougar & 2.0 & 0.1 & 27.4 & 59.1 & 4.8 & 2.3 \\
\hline Wolf & 2.2 & 0.1 & 24.9 & 55.3 & 8.0 & 2.3 \\
\hline All species & 1.4 & 0.0 & 29.4 & 61.2 & 2.0 & 1.6 \\
\hline
\end{tabular}

and surrounding area in Kentucky and Tennessee (Supplementary Material 2, Fig. 2b). In most states that contained contiguous tracts of cougar habitat, $>90 \%$ of suitable cougar habitat was also suitable for black bears and wolves (Supplementary Material 3). The model of potential cougar habitat was validated with an independent set of confirmed cougar locations from North Dakota; see LaRue \& Nielsen (2011) for results.

Approximately $42 \%$ of the study region was considered suitable habitat for wolves, with only four states containing $<29 \%$ suitable habitat (Supplementary Material 2, Fig. 1c). Large, contiguous areas of suitable habitat comprised nearly $35 \%$ of the study region (Supplementary Material 2, Fig. 2c). Nearly half of the states included in the model contained $>50,000 \mathrm{~km}^{2}$ of contiguous, suitable habitat for wolves (Supplementary Material 2, Fig. 2c). In most states contiguous tracts of suitable wolf habitat overlapped bear habitat extensively and cougar habitat almost entirely. Across the whole study area approximately one-third of suitable wolf habitat was also suitable for both black bears and cougars (Supplementary Material 3).

The mean habitat suitability value of pixels associated with wolf locations was $89 \%$ in Michigan, $85 \%$ in Minnesota and
$86 \%$ in Wisconsin (88\% overall). The percentage of locations with $\geq 75 \%$ suitability scores was $93 \%$ in Michigan, $85 \%$ in Minnesota and $85 \%$ in Wisconsin (91\% overall). The distributions of habitat suitability values associated with known locations of wolf and state-wide random locations differed for all three datasets $(D=0.562, \mathrm{P}<0.001$ for Michigan; $D=0.380, \mathrm{P}<0.001$ for Minnesota; $D=0.482, \mathrm{P}<0.001$ for Wisconsin).

\section{Discussion}

We provide the first large-scale combined model of biologically suitable habitat for black bears, cougars and wolves in the midwestern USA; validation procedures indicated this model was successful in identifying habitat used by each of the three carnivores. In addition to delineating variation in the geographical distribution of potential habitat among the three carnivores, the model shows where these species may establish breeding populations in the future and how these populations may overlap. It also highlights areas that will be vital to the persistence of these carnivores should more widespread recolonization of the Midwest occur. 

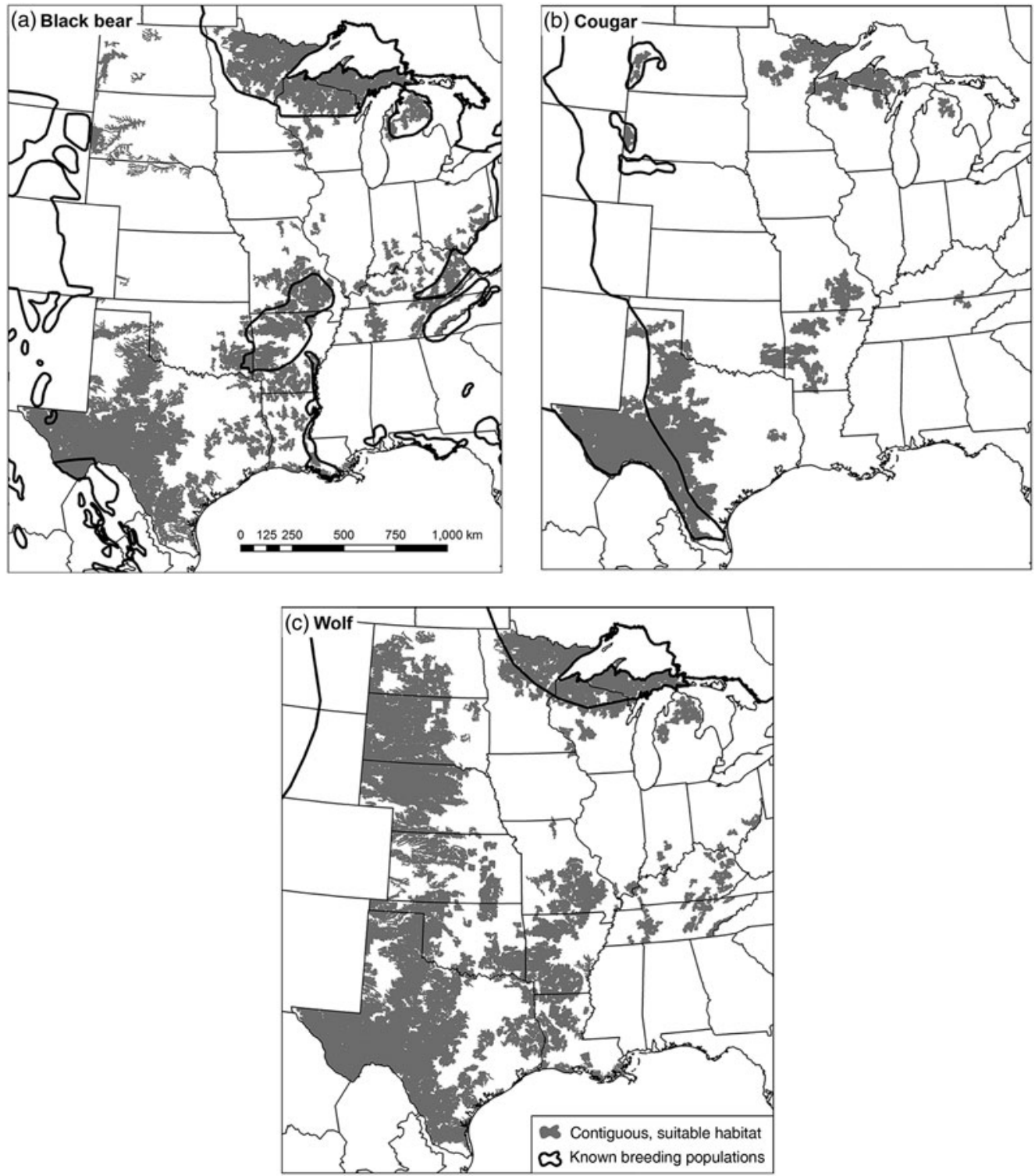

FIG. 2 Contiguous tracts of suitable habitat (expert-assisted scores $\geq 75 \%$ ) for (a) black bear, (b) cougar and (c) wolf in the midwestern USA.

Of the three species, wolves had the highest proportion and widest distribution of suitable habitat. Our model corroborated that of Mladenoff et al. $(1995,2009)$, who delineated approximately the same amount of wolf habitat in Minnesota, Wisconsin and Michigan within occupancy classes with $\geq 75 \%$ probability. The expert-assisted scores used to build the wolf habitat model reflected that wolves are generally non-specific to particular vegetation and ecosystem types; factors correlated to human activity, such as land ownership, road density and human population density, have greater influence over where wolves can maintain populations (Paquet \& Carbyn, 2003). Wolves differed from black bears and cougars in that experts considered human population density to be more influential than cover type. Wolves can adapt to live in nearly any habitat where they are tolerated by humans and have adequate prey (Mech, 1995); they once occurred in forests, grasslands, deserts and tundra (Paquet \& Carbyn, 2003). In addition to broad habitat tolerance, wolves are capable of rapid, long-distance movement, a factor that played a significant role in their swift recolonization of the Great Lakes Region (Treves et al., 2009). The majority of wolves leave their natal packs and both sexes are equally likely to disperse (Treves et al., 2009), a life-history trait that facilitates recolonization.

The models predicted c. $25 \%$ less suitable habitat for black bears than for wolves in the study region. In contrast with wolves, cover type was the most influential habitat variable for black bears. Although black bears are habitat generalists, their ideal habitat consists of rugged terrain, dense understorey vegetation, and food sources in the form of 
hard or soft mast; such habitat characteristics become more crucial when human populations expand into bear habitat (Pelton, 2003). Large, contiguous tracts of forest cover are fragmented across the study region, which may explain why the models predicted fewer contiguous tracts of suitable bear habitat than wolf habitat, particularly in the Great Plains. Although suitable habitat is distributed patchily throughout the study region, black bears are capable of longdistance movement (albeit more typical for males) and existing in small breeding populations (Maehr et al., 2003), thus the establishment of viable breeding populations in such areas is possible.

Of the three focal carnivores, cougars had the lowest proportion of suitable habitat in the region, less than half the area of suitable wolf habitat. Cougars require vegetative or topographic stalking cover and favour rugged terrain and higher elevations, whereas they avoid open areas such as agricultural land or grasslands (Pierce \& Bleich, 2003). Agricultural land was twice as important for black bears as for cougars, and mixed forest was assigned a higher weight for cougar habitat than for black bear habitat. Additionally, we designated a higher minimum threshold for contiguous habitat area for cougars than for black bears or wolves on the basis of population analyses by Beier (1993) and Belden \& Hagedorn (1993). These factors may partially explain why, of the three carnivores, cougars have the least suitable habitat in the region. Recolonization of currently unoccupied suitable habitat is possible because cougars are known to disperse distances $>500 \mathrm{~km}$ (Thompson \& Jenks, 2005; Stoner et al., 2008) and traverse matrices of non-cougar habitat (Sweanor et al., 2000). Establishment of viable breeding populations of cougars in such areas will depend largely on dispersal of females. Female cougars are more likely than males to be philopatric and to travel shorter distances (Sweanor et al., 2000; Thompson \& Jenks, 2010), although emigration and dispersal distance may be influenced by human-caused mortality and the presence of wolves (Newby et al., 2013).

The combined habitat models show considerable overlap in contiguous, suitable habitat for the three species, particularly for black bears and wolves. Wolves are sympatric with black bears nearly everywhere in their range in the USA and Canada, and all three carnivores inhabit areas of the western USA, such as Yellowstone National Park (Ruth et al., 2003). Although territorial or agonistic interactions and fatal encounters have been observed among all three species (Rogers \& Mech, 1981; Boyd \& Neale, 1992; Jimenez et al., 2008), they are known to coexist through temporal and resource partitioning (Kortello et al., 2007). However, cougars are vulnerable to interference and exploitation competition from wolves and bears; cougars frequently lose their kills to wolf packs and bears (Ruth \& Murphy, 2010). Moreover, competition with wolves for prey may be exacerbated in winter when prey becomes more concentrated as a result of accumulating snow (Ruth \& Murphy, 2010). Thus, the presence of wolves or bears may limit the use of suitable habitat by cougars, especially in regions that experience heavy snow. Black bears may be more successful in recolonizing suitable habitat than cougars and wolves because potential source populations of black bears are much more widespread than cougar or wolf populations. Cougars and wolves compete more directly for prey (Kunkel et al., 1999; Alexander et al., 2006) and are generally perceived more negatively than bears by the public (Kellert, 1994; Campbell \& Lancaster, 2010).

The habitat models performed well when validated with independent sets of locations from states with breeding populations. However, there are limitations to modelling carnivore habitat on a large scale using expert knowledge-based models. Although the expert knowledge used to weight each habitat variable may be an excellent predictor of suitable carnivore habitat in certain locations, applying it across a large study region is bound to result in fine-scale inaccuracies. For example, the model predicted that black bears have $>300,000 \mathrm{~km}^{2}$ of contiguous area in Texas suitable for expansion, based on low human and road densities and the presence of intermittent streams; other studies have also shown suitable habitat for black bears in the Trans-Pecos (Rice et al., 2009) and south-eastern regions (Morzillo et al., 2011) of Texas. However, Rice et al. (2009) highlighted the lack of water resources in the desert environment of Texas as well as the presence of agricultural areas that are primarily associated with cattle production rather than crops; thus food and water availability at lower elevations across Texas are probably insufficient to sustain viable populations of black bears.

We did not incorporate prey abundance into the models because prey density is not always a good predictor of suitable carnivore habitat (Mladenoff et al., 1995) and reliable regional datasets were unavailable. We used land cover as a surrogate for prey abundance, which is generally a safe assumption throughout the study region (Roseberry \& Woolf, 1998). However, in the heavily forested region of northeastern Minnesota designated suitable for all three focal carnivores, deer populations are seasonally low and deer have been unable to recolonize the area in substantial numbers (Nelson \& Mech, 2006). Competition for prey in this area may render it unsuitable for viable populations of all three focal species, although wolves persist by preying on moose Alces alces (Nelson \& Mech, 2006).

Large carnivores are capable of recolonizing areas previously thought to be unsuitable or too isolated or fragmented to maintain viable populations (Hoffman \& Genoways, 2005; Mladenoff et al., 2009), and therefore the amount of suitable habitat predicted by the models may be too conservative in some areas. For example, the Pine Ridge area of Nebraska sustains a breeding population of cougars (Wilson et al., 2010) but is too fragmented to be designated 
a contiguous habitat tract by the model; such inaccuracy also occurs in the black bear habitat model, for eastern Tennessee. Despite localized errors, the habitat models were robust overall and should prove to be useful predictors of potential habitat for black bears, cougars and wolves on a large scale.

\section{Conservation implications}

Black bears, cougars and wolves are already recolonizing the Midwest in certain areas (Bales et al., 2005; Wydeven et al., 2009; LaRue et al., 2012) and we believe this trend will continue. The habitat models serve as a valuable tool to predict where viable breeding populations of large carnivores may establish in the study region if recolonization becomes more widespread; they are less useful for describing carnivore dispersal habitat. Large carnivores are known to traverse vast expanses of human-dominated areas during dispersal (Thompson \& Jenks, 2005); as such, they will not always be found in areas deemed suitable.

States projected to gain populations of previously extirpated large carnivores should prepare for novel management challenges, particularly if the state has never had a breeding population of large carnivores since the advent of modern wildlife management (e.g., Illinois, Indiana, Iowa and Kansas). The models predict that all states in the study region may contain enough contiguous, suitable habitat for a breeding population of at least one of the focal species to establish. The legal status of black bears, cougars, and wolves varies widely by state; black bears and cougars are protected in some states but hunted or considered extirpated in others; wolves are federally designated as endangered except within the boundaries of their distinct population segment (USFWS, 2012), where they are hunted in some states and protected in others. We recommend that those states in the study region without breeding populations of these species consider developing conservation plans for them, as well as incorporating them into wildlife codes.

Proactively planning for carnivore recolonization will allow wildlife agencies to prepare for potential impacts on ecosystems (particularly ungulate prey and mesopredators) and human-carnivore conflict; it may also influence management and policy decisions. Public attitudes towards large carnivores may ultimately determine the species' fate in the Midwest (Smith et al., 2014). Maps of potential habitat can inform and direct outreach and educational initiatives intended for residents who have lived in the absence of large carnivores for virtually a century. The maps could also assist midwestern states in efforts to assess residents' attitudes regarding the re-establishment of large carnivores, to evaluate movement corridors that link or pose barriers between suitable habitats, and to develop appropriate management plans. Contiguous, suitable habitat tracts for black bears, cougars and wolves in the study region typically span multiple states. As large carnivores do not heed refuge or state borders, coordination across boundaries and among agencies is vital to successful carnivore management (Noss, 1983; Forbes \& Theberge, 1996).

Although the conservation outlook for large carnivores has been dire during the last century and remains bleak for species such as tigers Panthera tigris and African wild dogs Lycaon pictus (Weber \& Rabinowitz, 1996), the expansion of large carnivores in North America and Europe portends the future in areas where modern management policies aimed at carnivore conservation are implemented. Weber \& Rabinowitz (1996) contended that North America has a poor record of conserving large carnivores and should follow approaches used by other countries. However, the re-establishment and continued expansion of black bear, cougar and wolf populations in the USA would not have occurred without source populations that were protected and managed appropriately. The recovery of these species, along with brown bears Ursus arctos, Eurasian lynx Lynx lynx and wolves in Europe (Swenson et al., 1995; Breitenmoser, 1998), show that where legislation is favourable to large carnivores, populations can resurge and recolonize areas whence they were extirpated, even as human populations increase (Linnell et al., 2001). Simple, easily developed habitat models may be invaluable for mapping species expansion and informing future conservation efforts.

\section{Acknowledgements}

This project was funded by the Illinois Department of Natural Resources Federal Aid Project W-163-R. The Cooperative Wildlife Research Laboratory, Graduate School, College of Science, and College of Agricultural Sciences at Southern Illinois University Carbondale provided support. We acknowledge M. LaRue for use of her cougar habitat model. We thank D. Beyer, M. Ditmer, J. Erb, K. Malcolm, F. van Manen and A. Wydeven for reviewing the expert-opinion surveys and/or providing carnivore locations for model validation. We thank L. Adams, J. Beringer, A. Bump, J. Clark, J. Erb, C. Hoving, J. Kanta, J. Kath, D. Mech, J. Olson, D. Onorato, M. Peek, R. Peterson, S. Prange, G. Roloff, C. Ryan, S. Tucker, M. Vaughan and S. Wilson for completing the expert-opinion surveys.

\section{References}

Alexander, S.M., Logan, T.B. \& Paquet, P.C. (2006) Spatio-temporal co-occurrence of cougars (Felis concolor), wolves (Canis lupus) and their prey during winter: a comparison of two analytical methods. Journal of Biogeography, 33, 2001-2012. 
Bales, S.L., Hellgren, E.C., Leslie, Jr, D.M. \& Hemphill, Jr, J. (2005) Dynamics of a recolonizing population of black bears in the Ouachita Mountains of Oklahoma. Wildlife Society Bulletin, 33, 1342-1351.

BEIER, P. (1993) Determining minimum habitat areas and habitat corridors for cougars. Conservation Biology, 7, 94-108.

Belden, R.C. \& Hagedorn, B.W. (1993) Feasibility of translocating panthers into northern Florida. The Journal of Wildlife Management, 57, 388-397.

Berger, K.M. \& Gese, E.M. (2007) Does interference competition with wolves limit the distribution and abundance of coyotes? Journal of Animal Ecology, 76, 1075-1085.

Berger, K.M., Gese, E.M. \& Berger, J. (2008) Indirect effects and traditional trophic cascades: a test involving wolves, coyotes, and pronghorn. Ecology, 89, 818-828.

Boyd, D.K. \& Neale, G.K. (1992) An adult cougar, Felis concolor, killed by gray wolves, Canis lupus, in Glacier Nation Park, Montana. Canadian Field Naturalist, 106, 524-525.

Breitenmoser, U. (1998) Large predators in the Alps: the fall and rise of man's competitors. Biological Conservation, 83, 279-289.

Campbell, M. \& Lancaster, B. (2010) Public attitudes toward black bears (Ursus americanus) and cougars (Puma concolor) on Vancouver Island. Society and Animals, 18, 40-57.

DelGiudice, G.D., Riggs, M.R., Joly, P. \& PAN, W. (2002) Winter severity, survival, and cause-specific mortality of female white-tailed deer in north-central Minnesota. The Journal of Wildlife Management, 66, 698-717.

Feldhamer, G.A., Thompson, B.C. \& Chapman, J.A. (eds) (2003) Wild Mammals of North America: Biology, Management, and Conservation, 2nd edition. The Johns Hopkins University Press, Baltimore, USA.

Forbes, G.J. \& Theberge, J.B. (1996) Cross-boundary management of Algonquin Park wolves. Conservation Biology, 10, 1091-1097.

Fritts, S.H. \& CARbyn, L.N. (1995) Population viability, nature reserves, and the outlook for gray wolf conservation in North America. Restoration Ecology, 3, 26-38.

Garshelis, D.L. \& Hristienko, H. (2006) State and provincial estimates of American black bear numbers versus assessments of population trend. Ursus, 17, 1-7.

Garshelis, D.L., Noyce, K.V. \& Ditmer, M.A. (2011) Ecology and population dynamics of black bears in Minnesota. In Summaries of Wildlife Research Findings (eds G.D. DelGiudice, M. Grund, J.S. Lawrence \& M.S. Lenarz), pp. 103-114. Minnesota Department of Natural Resources, St. Paul, USA.

Hebblewhite, M., White, C.A., Nietvelt, C.G., McKenzie, J.A., Hurd, T.E., Fryxell, J.M. et al. (2005) Human activity mediates a trophic cascade caused by wolves. Ecology, 86, 2135-2144.

Hellgren, E.C., Bales, S.L., Gregory, M.S., Leslie, Jr, D.M. \& Clark, J.D. (2007) Testing a Mahalanobis distance model of black bear habitat use in the Ouachita Mountains of Oklahoma. The Journal of Wildlife Management, 71, 924-928.

Hoffman, J.D. \& Genoways, H.H. (2005) Recent records of formerly extirpated carnivores in Nebraska. The Prairie Naturalist, $37,225-245$

Jimenez, M.D., Asher, V.J., Bergman, C., Bangs, E.E. \& Woodruff, S.P. (2008) Gray wolves, Canis lupus, killed by cougars, Puma concolor, and a grizzly bear, Ursus arctos, in Montana, Alberta, and Wyoming. The Canadian Field Naturalist, 122, 76-78.

Kellert, S.R. (1994) Public attitudes toward bears and their conservation. Proceedings of the International Conference on Bear Research and Management, 9, 43-50.

Kortello, A.D., Hurd, T.E. \& Murray, D.L. (2007) Interactions between cougars (Puma concolor) and gray wolves (Canis lupus) in Banff National Park, Alberta. Ecoscience, 14, 214-222.
Kunkel, K.E., Ruth, T.K., Pletscher, D.H. \& Hornocker, M.G. (1999) Winter prey selection by wolves and cougars in and near Glacier National Park, Montana. The Journal of Wildlife Management, 63, 901-910.

Laliberte, A.S. \& Ripple, W.J. (2004) Range contractions of North American carnivores and ungulates. BioScience, 54, 123-138.

LaRue, M.A. \& Nielsen, C.K. (2011) Modelling potential habitat for cougars in midwestern North America. Ecological Modelling, 222, 897-900.

LaRue, M.A., Nielsen, C.K., Dowling, M., Miller, K., Wilson, B., ShaW, H. \& ANDERSON, JR, C.R. (2012) Cougars are recolonizing the midwest: analysis of cougar confirmations during 1990-2008. The Journal of Wildife Management, 76, 1364-1369.

Linnell, J.D.C., Swenson, J.E. \& Anderson, R. (2001) Predators and people: conservation of large carnivores is possible at high human densities if management policy is favourable. Animal Conservation, 4, 345-349.

Maehr, D.S., Smith, J.S., Cunningham, M.W., Barnwell, M.E., Larkin, J.L. \& OrLando, M.A. (2003) Spatial characteristics of an isolated Florida black bear population. Southeastern Naturalist, 2, 433-446.

Malcolm, K.D. (2011) Responses of two ecologically similar bear species (American black bear and Asiatic black bear) to human-dominated landscapes and consumptive use. $\mathrm{PhD}$ thesis. University of Wisconsin, Madison, USA.

$\mathrm{MeCH}$, L.D. (1995) The challenge and opportunity of recovering wolf populations. Conservation Biology, 9, 270-278.

Mladenoff, D.J., Clayton, M.K., Pratt, S.D., Sickley, T.A. \& Wydeven, A.P. (2009) Change in occupied wolf habitat in the northern Great Lakes region. In Recovery of Gray Wolves in the Great Lakes Region of the United States (eds A.P. Wydeven, T.R. Van Deelen \& E.J. Heske), pp. 119-138. Springer Science, New York, USA.

Mladenoff, D.J., Sickley, T.A., Haight, R.G. \& Wydeven, A.P. (1995) A regional landscape analysis and prediction of favorable gray wolf habitat in the northern Great Lakes region. Conservation Biology, 9, 279-294.

Morzillo, A.T., Ferrari, J.R. \& LiU, J. (2011) An integration of habitat evaluation, individual based modeling, and graph theory for a potential black bear population recovery in southeastern Texas, USA. Landscape Ecology, 26, 69-81.

MRlC (Multi-Resolution Land Characteristics Consortium) (2006) National land cover dataset. Http://www. mrlc.gov/index.php [accessed 18 May 2011].

Nelson, M.E. \& Mech, L.D. (2006) A 3-decade dearth of deer (Odocoileus virginianus) in a wolf (Canis lupus)-dominated ecosystem. American Midland Naturalist, 155, 373-382.

Newby, J.R., Mills, L.S., Ruth, T.K., Pletscher, D.H., Mitchell, M.S., Quigley, H.B. et al. (2013) Human-caused mortality influences spatial population dynamics: pumas in landscapes with varying mortality risks. Biological Conservation, 159, 230-239.

Noss, R.F. (1983) A regional landscape approach to maintain diversity. BioScience, 33, 700-706.

Paquet, P.C. \& Carbyn, L.N. (2003) Gray wolf (Canis lupus and allies). In Wild Mammals of North America: Biology, Management, and Conservation, 2nd edition (eds G.A. Feldhamer, B.C. Thompson \& J.A. Chapman), pp. 482-510. The Johns Hopkins University Press, Baltimore, USA.

Pelton, M.R. (2003) Black bear (Ursus americanus). In Wild Mammals of North America: Biology, Management, and Conservation, 2nd edition (eds G.A. Feldhamer, B.C. Thompson \& J.A. Chapman), pp. 547-555. The Johns Hopkins University Press, Baltimore, USA.

Pierce, B.M. \& Bleich, V.C. (2003) Mountain lion (Puma concolor). In Wild Mammals of North America: Biology, Management, and Conservation, 2nd edition (eds G.A. Feldhamer, B.C. Thompson \& J. 
A. Chapman), pp. 744-757. The Johns Hopkins University Press, Baltimore, USA.

Prugh, L.R., Stoner, C.J., Epps, C.W., Bean, W.T., Ripple, W.J., Laliberte, A.S. \& Brashares, J.S. (2009) The rise of the mesopredator. BioScience, 59, 779-791.

Rice, M.B., Ballard, W.B., Fish, E.B., McIntyre, N.E. \& Holdermann, D. (2009) Habitat-distribution modeling of a recolonizing black bear, Ursus americanus, population in the Trans-Pecos region of Texas. The Canadian Field-Naturalist, 3, 246-254.

Ripple, W.J. \& Beschta, R.L. (2008) Trophic cascades involving cougar, mule deer, and black oaks in Yosemite National Park. Biological Conservation, 141, 1249-1256.

Robinson, H.S., Wielgus, R.B. \& Gwilliam, J.C. (2002) Cougar predation and population growth of sympatric mule deer and white-tailed deer. Canadian Journal of Zoology, 8o, 556-568.

Rogers, L.L. \& Allen, A.W. (1987) Habitat suitability index models: black bear, upper Great Lakes region. U.S. Fish and Wildlife Service Biological Report 82 (10.144). U.S. Department of the Interior, Washington, D.C., USA.

Rogers, L.L. \& MECH, L.D. (1981) Interactions of wolves and black bears in northeastern Minnesota. Journal of Mammalogy, 62, 434-436.

Roseberry, J.L. \& Woolf, A. (1998) Habitat-population density relationships for white-tailed deer in Illinois. Wildlife Society Bulletin, 26, 252-258.

Ruth, T.K. \& MurPhy, K. (2010) Competition with other carnivores for prey. In Cougar: Ecology and Conservation (eds M. Hornocker \& S. Negri), pp. 163-172. The University of Chicago Press, Chicago, USA.

Ruth, T.K., Smith, D.W., Haroldson, M.A., Buotte, P.C., Schwartz, C.C., Quigley, H.B. et al. (2003) Large-carnivore response to recreational big-game hunting along the Yellowstone National Park and Absaroka-Beartooth Wilderness boundary. Wildlife Society Bulletin, 31, 1150-1161.

SAaty, T.L. (1980) The Analytic Hierarchy Process: Planning, Priority Setting, Resource Allocation. McGraw-Hill International Book Co., New York, USA.

Smith, J.B., Nielsen, C.K. \& Hellgren, E.C. (2014) Illinois resident attitudes toward recolonizing large carnivores. The Journal of Wildlife Management, 78, 930-943.

Stoner, D.C., Rieth, W.R., Wolfe, M.L., Mecham, M.B. \& Neville, A. (2008) Long-distance dispersal of a female cougar in a basin and range landscape. The Journal of Wildlife Management, 72, 933-939.

STORE, R. \& Kangas, J. (2001) Integrating spatial multi-criteria evaluation and expert knowledge for GIS-based habitat suitability modelling. Landscape and Urban Planning, 55, 79-93.

Sweanor, L.L., Logan, K.A. \& Hornocker, M.G. (2000) Cougar dispersal patterns, metapopulation dynamics, and conservation. Conservation Biology, 14, 798-808.

Swenson, J.E., Wabakken, P., Sandegren, F., Bjärvall, A., Franzén, R. \& Söderberg, A. (1995) The near extinction and recovery of brown bears in Scandinavia in relation to the bear management policies of Norway and Sweden. Wildlife Biology, 1, $11-25$.

Thompson, D.J. \& Jenks, J.A. (2005) Research notes: longdistance dispersal by a subadult male cougar from the Black Hills, South Dakota. The Journal of Wildlife Management, 69, 818-820.

Thompson, D.J. \& Jenks, J.A. (2010) Dispersal movements of subadult cougars from the Black Hills: the notions of range expansion and recolonization. Ecosphere, 1, 1-11.

Treves, A., Martin, K.A., Wiedenhoeft, J.E. \& Wydeven, A.P. (2009) Dispersal of gray wolves in the Great Lakes Region. In Recovery of Gray Wolves in the Great Lakes Region of the United States (eds A.P. Wydeven, T.R. Van Deelen \& E.J. Heske), pp. 191-204. Springer Science, New York, USA.

U.S. Census Bureau (2010a) 2010 TIGER/Line ${ }^{\star}$ shapefiles: block groups. Http://www.census.gov [accessed June 2011].

U.S. Census Bureau (2010b) 2010 TIGER/Line ${ }^{\diamond}$ shapefiles: roads. Http://www.census.gov [accessed June 2011].

USFWS (United States Fish \& Wildlife Service) (2012) Gray wolves in the western Great Lakes states. Http://www.fws.gov/ midwest/wolf/ [accessed November 2012].

USGS (United States Geological Survey) (2011) National elevation dataset. Http://seamless.usgs.gov [accessed June 2011].

Valière, N., Fumagalli, L., Gielly, L., Miquel, C., Lequette, B., Poulle, M.-L. et al. (2003) Long-distance wolf recolonization of France and Switzerland inferred from non-invasive genetic sampling over a period of 10 years. Animal Conservation, 6, 83-92.

Weber, W. \& Rabinowitz, A. (1996) A global perspective on large carnivore conservation. Conservation Biology, 10, 1046-1054.

Wickham, J.D., Stehman, S.V., Gass, L., Dewitz, J., Fry, J.A. \& WADE, T.G. (2013) Accuracy assessment of NLCD 2006 land cover and impervious surface. Remote Sensing of Environment, 130, 294-304.

Wilson, S., Hoffman, J.D. \& Genoways, H.H. (2010) Observations of reproduction in mountain lions from Nebraska. Western North American Naturalist, 70, 238-240.

Woodroffe, R. (2000) Predators and people: using human densities to interpret declines of large carnivores. Animal Conservation, 3, 165-173.

Wydeven, A.P., Van Deelen, T.R. \& Heske, E.J. (eds) (2009) Recovery of Gray Wolves in the Great Lakes Region of the United States. Springer Science, New York, USA.

\section{Biographical sketches}

Julia Smith's research interests include ecology, conservation and recovery of large carnivores, habitat and corridor modelling, and human dimensions of carnivore management. CLAYTON NielSEN's research interests include ecology, management and conservation of mammalian wildlife species, and population dynamics of wildlife. ERIC HELLGREN's research interests are focused on questions of population and habitat ecology in primarily mammalian systems. 